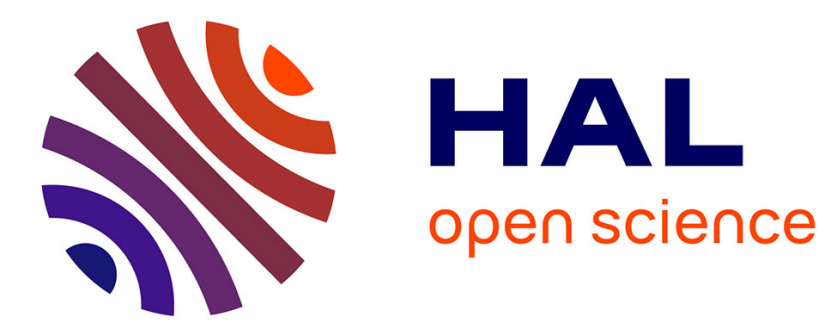

\title{
Dynamic glass transition of filled polysiloxane upon electron irradiation
}

Aurélien Roggero, Eric Dantras, Thierry Paulmier, Claire Tonon, Simon

Lewandowski, Sabine Dagras, Denis Payan

\section{To cite this version:}

Aurélien Roggero, Eric Dantras, Thierry Paulmier, Claire Tonon, Simon Lewandowski, et al.. Dynamic glass transition of filled polysiloxane upon electron irradiation. Journal of Non-Crystalline Solids, 2017, vol. 455, pp. 17-23. 10.1016/j.jnoncrysol.2016.10.025 . hal-01440333

\section{HAL Id: hal-01440333 \\ https://hal.science/hal-01440333}

Submitted on 19 Jan 2017

HAL is a multi-disciplinary open access archive for the deposit and dissemination of scientific research documents, whether they are published or not. The documents may come from teaching and research institutions in France or abroad, or from public or private research centers.
L'archive ouverte pluridisciplinaire $\mathbf{H A L}$, est destinée au dépôt et à la diffusion de documents scientifiques de niveau recherche, publiés ou non, émanant des établissements d'enseignement et de recherche français ou étrangers, des laboratoires publics ou privés. 


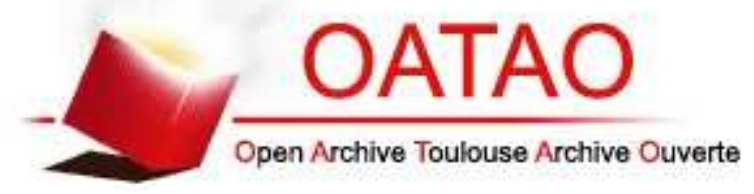

\section{Open Archive TOULOUSE Archive Ouverte (OATAO)}

OATAO is an open access repository that collects the work of Toulouse researchers and makes it freely available over the web where possible.

This is an author-deposited version published in : http://oatao.univ-toulouse.fr/ Eprints ID : 17433

To link to this article : DOI : 10.1016/j.jnoncrysol.2016.10.025

URL : http://dx.doi.org/10.1016/j.jnoncrysol.2016.10.025

To cite this version : Roggero, Aurélien and Dantras, Eric and Paulmier, Thierry and Tonon, Claire and Lewandowski, Simon and Dagras, Sabine and Payan, Denis Dynamic glass transition of filled polysiloxane upon electron irradiation. (2017) Journal of NonCrystalline Solids, vol. 455. pp. 17-23. ISSN 0022-3093

Any correspondence concerning this service should be sent to the repository administrator: staff-oatao@ listes-diff.inp-toulouse.fr 


\title{
Dynamic glass transition of filled polysiloxane upon electron irradiation
}

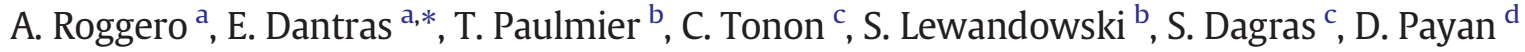 \\ a Physique des Polymères CIRIMAT, Université de Toulouse, Université Paul Sabatier, 108 route de Narbonne, Bât. 3R1b2, 31062 Toulouse Cedex 9, France \\ b ONERA, The French Aerospace Lab, F-31055, France \\ c Airbus Defence and Space, 31 Avenue des Cosmonautes, 31402 Toulouse, France \\ d Centre National d'Etudes Spatiales, 18 Avenue Edouard Belin, 31400 Toulouse, France
}

\begin{abstract}
A B S T R A C T
The influence of radiation-induced crosslinking on the molecular mobility of a filled silicone elastomer near the glass transition ( $\alpha$-relaxation) was analyzed using broadband dielectric spectroscopy. Samples of the isolated polysiloxane matrix (neat) were also studied so as to assess the filler influence on the evolution of the $\alpha$ relaxation.

A slowing-down of the segmental dynamics was observed with increasing ionizing dose. It was ascribed to the relaxing dipoles losing degrees of freedom as a result of network stiffening. An enhancement of intermolecular coupling, associated with the cooperativity of the $\alpha$-relaxation, was deduced from the dielectric analysis. Similar observations were made in the past with chemically crosslinked polysiloxanes. This study evidenced that even though the crosslinks formed upon chemical crosslinking (mainly $\mathrm{Si}-\mathrm{CH}_{2}-\mathrm{CH}_{2}-\mathrm{Si}$ ) differ in nature from those formed upon irradiation (mainly $\mathrm{SiO}_{3}$ and $\mathrm{SiO}_{4}$ ), they affect the dynamic glass transition in a very similar way.

The filler influence on the dynamic glass transition was also studied upon irradiation. One of the main outcomes of this study is the fading of the filler-related effect in the most irradiated samples: both the shape and dynamics of the $\alpha$-relaxation were identical in the most highly irradiated neat and filled samples.
\end{abstract}

passed within the field of materials ageing in focused on a silicone elastomer used as an adinded assemblies for communication satellites.

[1], the structural evolution of a space-used filled silicone elastomer exposed to high energy electrons was investigated. A preferential crosslinking process of the polysiloxane matrix was observed, involving the formation of $\mathrm{SiO}_{3}$ bonds in the network. Moreover, the inorganic fillers (silica and iron oxide) were shown to cause further radiation-induced crosslinking through the formation of $\mathrm{SiO}_{4}$ bonds at the filler-matrix interfaces. This additional crosslinking process resulted in an increase in mechanical modulus upon irradiation that was more pronounced in the filled samples than in the isolated matrix (neat samples). On another hand, scanning calorimetry measurements showed no significant filler influence on the evolution of the glass transition temperature.

The $\alpha$-relaxation of model linear PolyDiMethylSiloxane (PDMS) [2-4] and PolyMethylPhenylSiloxane (PMPS) [5,6] has been studied thoroughly, partly because neither secondary relaxations (they occur

\footnotetext{
* Corresponding author.

E-mail address: eric.dantras@univ-tlse3.fr (E. Dantras).
}

at much lower temperatures) nor electrical conductivity (observed at higher temperatures) interfere with it. Broadband Dielectric Spectroscopy proved to be a particularly adequate tool for that purpose. Regarding three-dimensional polymer networks, multiple studies involving a variety of polymers [7-10] - including silicone networks [11,12] - led to the general conclusion that an increasing degree of crosslinking results in a slowing-down of the $\alpha$-relaxation dynamics, as well as a more pronounced deviation from Arrhenius behavior: crosslinked polymers tend to be more fragile than linear ones with the same backbone. In such studies, the degree of crosslinking is generally controlled chemically (i.e. by varying hardener proportion). Polyadditive crosslinking of the two components-RTV silicone rubbers mainly proceeds through the formation of silethylene links $\left(\mathrm{Si}-\mathrm{CH}_{2}-\mathrm{CH}_{2}-\mathrm{Si}\right)$ [13], while radiationinduced crosslinking primarily involves the formation of $\mathrm{SiO}_{3}$ crosslinks $[1,14]$.

Silicone elastomers for space applications are filled with inorganic particles. Silica fillers are undoubtedly the most used as they enhance their mechanical properties [15]. Fillers incorporated in a polysiloxane matrix affect the $\alpha$-relaxation: it is generally accepted that a polymer layer of reduced mobility ( a few $\mathrm{nm}$ ) is formed at the surface of the fillers [16]. The filler influence on the $\alpha$-relaxation mainly depends on their geometry, relative quantity, and on their interactions with the matrix. 
The present study aims at assessing the influence of the crosslinks nature (chemical or radiation-induced) on the $\alpha$-relaxation of a silicone elastomer. It will also bring insight in the filler influence on the dynamic glass transition throughout chemical ageing, which has not been studied yet.

\section{Materials and methods}

\subsection{Materials}

The studied material is a commercial (Wacker) two components silicone elastomer which crosslinks at room temperature (RTV, Room Temperature Vulcanization). Part A mainly consists of a poly(dimethylsiloxane-co-methylphenylsiloxane) resin (approx. $35 \mathrm{wt} \%$ ) mixed with crystalline silica ( $\alpha$-quartz particles of the glass splinter type, the size of which is comprised in the range [0.2-20 $\mu \mathrm{m}])$ and iron(III) oxide (spherical particle size in the range [0.1-1 $\mu \mathrm{m}]$ ) fillers. Part B is a hardener containing a Pt catalyst responsible for polymerization. A filtering process performed on part A allowed separation and removal of the fillers from the resin. Consecutive polymerization with unmodified part B allowed the elaboration of neat samples (no fillers), as opposed to filled unmodified samples (with fillers).

The two components are manually mixed (weight ratio 9:1, according to data sheet) and poured into a mold consisting of a $50 \times 50 \mathrm{~mm}^{2}$ aluminum substrate the borders of which had been covered with aluminum tape. Even though this material is able to crosslink at room temperature, a curing process of $6 \mathrm{~h}$ at $100{ }^{\circ} \mathrm{C}$ was performed after mixing in order to enhance sample reproducibility.

The glass transition temperature of both filled and neat materials were measured at $-117 \pm 1{ }^{\circ} \mathrm{C}$, suggesting a low phenyl side groups content (the phenylmethylsiloxane mass fraction was estimated to be approximately $10 \%[17])$.

\subsection{Electron irradiations}

Electron irradiations were performed under secondary vacuum in the SIRENE facility at ONERA [18]. The procedure and dose calculations are detailed elsewhere [1] and summarized here. $150 \mu \mathrm{m}$-thick elastomer films were irradiated using a $400 \mathrm{keV}$-Van de Graaff electron accelerator along with a scattering foil in order to uniformly expose the sample surface. Ionizing doses up to $1.410^{6}$ Gy were achieved in $<12 \mathrm{~h}$ thanks to high beam currents in the order of $10 \mathrm{nA} \cdot \mathrm{cm}^{-2}$. Ionizing dose $\mathrm{D}$ expressed in Grays ( $1 \mathrm{~Gy}=1 \mathrm{~J} \cdot \mathrm{kg}^{-1}$ ) is defined by Eq. (1).

$\mathrm{D}=\Phi \frac{1}{\mathrm{~d}}\left(\frac{\mathrm{dE}}{\mathrm{dx}}\right)$

where $\Phi$ is the particle fluence, $\mathrm{d}$ the material density and $\mathrm{dE} / \mathrm{dx}$ the energy lost by an incident particle by unit length travelled in the material.

The samples irradiated in this way are uniformly aged and the indicated doses are mean values in the middle of the films.

\subsection{Broadband dielectric spectroscopy}

Broadband Dielectric Spectroscopy (BDS) measurements were performed isothermally in the frequency range $\left[10^{-2}-10^{6} \mathrm{~Hz}\right]$ on $150 \mu \mathrm{m}$-thick films placed between gold-plated stainless steel electrodes (30 mm diameter), using a Novocontrol BDS 4000 impedance analyzer.

Complex dielectric permittivities (Eq. (2)) were calculated from the experimental values of impedance.

$$
\varepsilon^{*}(\omega)=\varepsilon^{\prime}(\omega)-\mathrm{i} \varepsilon^{\prime \prime}(\omega)=\frac{1}{\mathrm{i} \omega \mathrm{C}_{0} \mathrm{Z}^{*}(\omega)}
$$

where $\varepsilon^{\prime}$ is the real component of the complex dielectric permittivity, $\varepsilon^{\prime \prime}$ its imaginary component, $C_{0}$ the capacitance in air and $Z^{*}$ the complex impedance.

The Havriliak-Negami parametric equation (see Eq. (3)) and the Schönhals-Schlosser model (see Eqs. (7a) and (7b)) were used to perform the fits of the experimental data.

\section{Results and discussion}

First of all, in the ionizing dose range performed in this study, the crosslink densities of the materials were previously shown to be linearly increasing functions of absorbed ionizing dose [1], in agreement with Delides and Shepherd [19] who observed a linear increase of crosslink density up to $1.610^{6} \mathrm{~Gy}$ of $\gamma$-rays in PDMS. In this section, the 'ionizing dose' abscissae in most of the figures are therefore proportionally linked to the 'crosslink density' of the samples.

\subsection{Crosslinking-induced constraints on the $\alpha$-relaxation}

In Fig. 1 are represented the Broadband Dielectric Spectroscopy (BDS) loss spectra obtained at $-105{ }^{\circ} \mathrm{C}$ from pristine and irradiated filled samples. The glass transition manifests as a well-defined dielectric loss peak. This is mainly due to the absence of crystallization peak - hindered by both the crosslinks of the network and the phenyl side groups $[20]$ - and local segmental $\beta$-relaxation in the vicinity of the $\alpha$ relaxation. With increasing ionizing dose, the maximum of the peak is shifted to lower frequencies, its intensity decreases, and its breadth increases.

The spectra in Fig. 1 were individually normalized to the coordinates of their respective maxima $\left(f_{\max }, \varepsilon^{\prime \prime}{ }_{\max }\right)$. They are represented in the inset of Fig. 1. The increase in the breadth of the peak is highlighted in the normalized spectra: the half-height width of the most irradiated sample is approximately 7 times larger than the pristine one. This broadening will be discussed in the subsection entitled "shape of the $\alpha$-relaxation loss peak".

In order to analyze the $\alpha$-relaxation segmental dynamics, the BDS isothermal dielectric loss comprising the relaxation (such as those in Fig. 1) were fitted using the Havriliak-Negami parametric equation [21]:

$\varepsilon^{*}=\varepsilon_{\infty}+\frac{\varepsilon_{\mathrm{S}}-\varepsilon_{\infty}}{\left(1+\left(i \omega \tau_{\mathrm{H}-\mathrm{N}}\right)^{\alpha_{\mathrm{H}-\mathrm{N}}}\right)^{\beta_{\mathrm{H}-\mathrm{N}}}}$

where $\varepsilon_{\mathrm{s}}$ and $\varepsilon_{\infty}$ are respectively the low and high frequency limits of the real relative permittivity, $\omega$ the angular frequency of the applied voltage, $\tau_{\mathrm{H}-\mathrm{N}}$ the mean relaxation time for the distribution of dipoles and $\alpha_{\mathrm{H}-\mathrm{N}}$ and $\beta_{\mathrm{H}-\mathrm{N}}$ adjustment parameters in the range [0-1] respectively controlling the breadth and the symmetry of the relaxation function.

Thus obtained $\tau_{\mathrm{H}-\mathrm{N}}$ are represented in the Arrhenius plot in Fig. 2 for the pristine and irradiated filled samples. The mean relaxation times

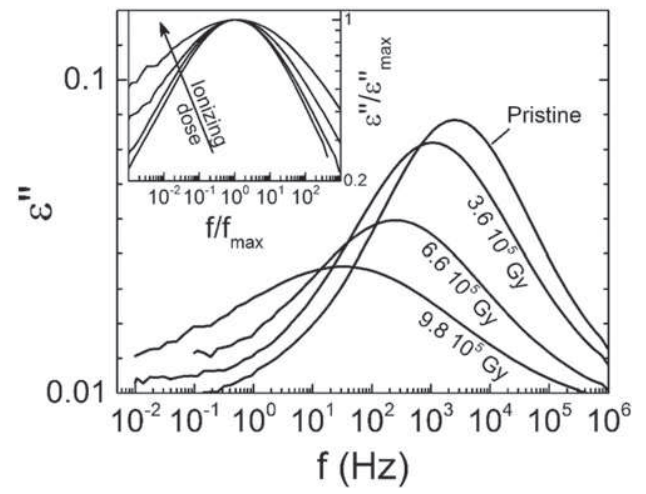

Fig. 1. BDS loss spectra at $-105^{\circ} \mathrm{C}$ of filled samples exposed to various ionizing doses. Inset: same spectra normalized to their respective maxima. 


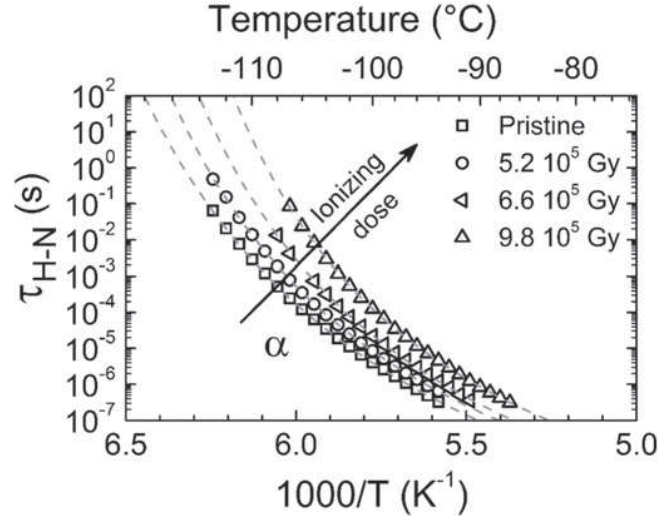

Fig. 2. Arrhenius plot of the Havriliak-Negami relaxation times associated with the $\alpha-$ relaxation of the filled material irradiated at various ionizing dose levels. Vogel-FulcherTammann fits are represented in dashed lines.

of the $\alpha$-relaxation increase with increasing ionizing dose, which is equivalent to the shifting of the $\alpha$-peak towards lower frequencies as observed in Fig. 1. As a result of network stiffening caused by increasing crosslink density, the relaxing dipoles lose degrees of freedom. In other words, the $\alpha$-relaxation is progressively slowed down.

The relaxation times in Fig. 2 were very satisfactorily fitted with the Vogel-Fulcher-Tammann (VFT) law [22]:

$\tau(\mathrm{T})=\tau_{0}^{\mathrm{VFT}} \mathrm{e}^{\frac{\mathrm{B}}{\left.\mathrm{T}-\mathrm{T}_{\infty}\right)}}=\tau_{0}^{\mathrm{VFT}} \mathrm{e}^{\frac{1}{\alpha_{\mathrm{f}}\left(\mathrm{T}-\mathrm{T}_{\infty}\right)}}$

where $\tau_{0}^{\mathrm{VFT}}$ is the pre-exponential factor, $\mathrm{B}$ a constant, $\alpha_{\mathrm{f}}$ the thermal expansion coefficient of free volume and $\mathrm{T}_{\infty}$ the Vogel temperature (below which there is no more free volume).

Various theoretical approaches (e.g. Adam-Gibbs model [23], free volume theory [25], coupling model by Ngai [24]) accounting for the VFT behavior of the $\alpha$-relaxation exist. The free volume approach was chosen because it allows the interpretation of the VFT fit parameter B, as the reciprocal thermal expansion coefficient of free volume $1 / \alpha_{\mathrm{f}}$ (see Eq. (4)). Before analyzing the evolution of the VFT fit parameters, the validity of the free volume approach was checked for the studied samples. Let aside the good mathematical match of the fit with the experimental points for all the samples, two physical arguments support the use of the VFT law to fit the experimental data in Fig. 2. The first one is the order of magnitude of the pre-exponential factor: $10^{-13}$ $10^{-12} \mathrm{~s}$ (see Fig. 3). Kremer and Schönhals reported that $10^{-13} \mathrm{~s}$ is

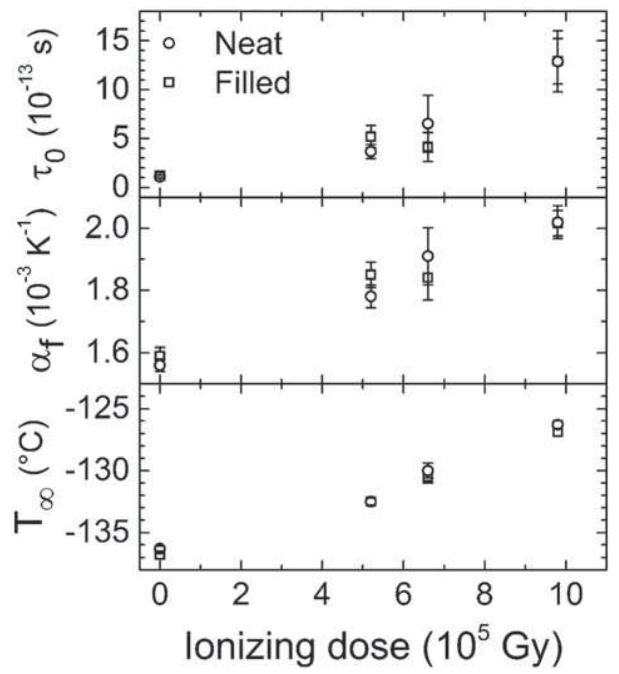

Fig. 3. Evolution of the VFT fit parameters with respect to ionizing dose for the neat and filled materials. the typical relaxation time of local orientational fluctuations in polymers [26] while Angell et al. considered the quasilattice vibration period $\left(10^{-14} \mathrm{~s}\right)$ to be a physically acceptable value for the VFT preexponential factor [27]. The second argument stems from the definition of the thermal expansion coefficient of free volume $\alpha_{\mathrm{f}}$ as the difference between the material's thermal expansion coefficients above and below the glass transition temperature [25]. Thermomechanical measurements were performed on a pristine neat sample and yielded the linear thermal expansion below and above the glass transition temperature: $0.1410^{-3} \mathrm{~K}^{-1}$ and $0.7010^{-3} \mathrm{~K}^{-1}$ respectively. As the neat material is homogeneous and isotropic, these values were multiplied by 3 to obtain the volumetric thermal expansion coefficients $\alpha_{\mathrm{v}}$ reported in Table 1. The difference between $\alpha_{v}$ above and below $T_{g}$ is $1.6810^{-3} \mathrm{~K}^{-1}$, which is in the same order of magnitude as $\alpha_{\mathrm{f}}=1.5610^{-3} \mathrm{~K}^{-1}$ (see Fig. 3), thus providing experimental validation of the definition of $\alpha_{\mathrm{f}}$ and a satisfactory correlation between thermomechanical and dielectric spectroscopy measurements. Such correlation could not be verified for the filled material due to the important filler content causing heterogeneity.

As seen in Fig. 3, the three VFT fit parameters increase linearly with respect to ionizing dose, for both the neat and filled materials. Schroeder and Roland [11] observed similar tendencies in chemically crosslinked PDMS networks. The evolutions of calorimetric $T_{g}$ on one hand, $\tau_{0}^{\mathrm{VFT}}$ and especially $\mathrm{T}_{\infty}$ on the other hand, are coherent with increasing crosslinking-induced constraints. The increase in $\alpha_{\mathrm{f}}$, however, was not expected as it qualitatively implies that while the network stiffens, free volume thermally expands more easily. Some insight might be given into this counterintuitive result by studying the cooperativity of the $\alpha$-relaxation.

3.2. Influence of network crosslinking on the intermolecular coupling and the local motions of the $\alpha$-relaxation

Two main contributions may account for the broadening of the $\alpha$ relaxation loss peak (Fig. 1). One of them is the segmental heterogenization introduced by the new crosslinks: the segments closer to the crosslinks are expected to have lower mobilities than those farther, resulting in a larger distribution of relaxation times. The other one is intermolecular cooperativity, a characteristic feature of the glass transition in polymers: the individual segmental motions are influenced by the motions of neighboring segments.

\subsubsection{Fragility evolution with respect to ionizing dose/crosslink density}

$\mathrm{T}_{\mathrm{g}}$-scaled plots were used by Angell [28] as a mean of classifying glass formers depending on the deviation of the $\alpha$-relaxation from Arrhenius behavior: strong liquids display Arrhenius dependence while fragile ones exhibit pronounced VFT behavior. The fragility index m, defined as the derivative of $\log \left(\tau_{\alpha}\right)$ in order of $\mathrm{T}_{\mathrm{g}} / \mathrm{T}$ calculated at $\mathrm{T}=\mathrm{T}_{\mathrm{g}}$ (Eq. (5)),

$\mathrm{m}=\left(\frac{\mathrm{d} \log \left(\tau_{\alpha}\right)}{\mathrm{d}\left(\mathrm{T}_{\mathrm{g}} / \mathrm{T}\right)}\right)_{\mathrm{T}=\mathrm{T}_{\mathrm{g}}}$

where $\tau_{\alpha}(T)=\tau_{H-N}(T)$ is the mean dipole relaxation time, and $T_{g}$ the calorimetric glass transition temperature, allows to quantify the deviation from Arrhenius behavior.

Table 1

Volumetric thermal expansion coefficients in the vicinity of the glass transition temperature (thermomechanical measurements) and thermal expansion coefficient of free volume (VFT fit of BDS data) of the pristine neat material.

\begin{tabular}{lll}
\hline$\alpha_{\mathrm{v}}\left[10^{-3} \mathrm{~K}^{-1}\right]$ & $\Delta \alpha_{\mathrm{v}}\left[10^{-3} \mathrm{~K}^{-1}\right]$ & $\alpha_{\mathrm{f}}$ (free volume) $\left[10^{-3} \mathrm{~K}^{-1}\right]$ \\
\hline 0.42 for $\mathrm{T}<\mathrm{T}_{\mathrm{g}}$ & 1.68 & 1.56 \\
2.10 for $\mathrm{T}>\mathrm{T}_{\mathrm{g}}$ & &
\end{tabular}


Roland and Ngai [29] actually discussed the applicability of the term "fragility" to polymers, which do not experience a modification of their chemical structure when passing the glass transition, and suggested the fragility plots could be called "cooperativity plots" instead. The physical meaning of fragility in polymers has indeed been thoroughly discussed since the 1980s. Experimental and theoretical correlations with other parameters of the glass transition have been investigated, the most conclusive of which was probably revealed by Böhmer et al. [30]. For a variety of amorphous polymeric materials, they evidenced a narrow correlation between fragility and nonexponentiality (that is the nonDebye nature of the relaxation). In 1979, Ngai developed the coupling model [24] which links the stretch exponent of the KohlrauschWilliams-Watts associated with the $\alpha$-relaxation to the strength of the intermolecular constraint. In this model, the shape of the relaxation function therefore varies according to the degree of cooperativity of the relaxation [31-35]. Under the light of the coupling model, the conclusion formulated by Böhmer et al. (fragility being correlated to nonexponentiality) suggests that fragility is to a great extent correlated to the cooperativity of the $\alpha$-relaxation.

A cooperativity plot of the pristine and irradiated filled samples is represented in Fig. 4. The temperature axis has been normalized to the calorimetric $\mathrm{T}_{\mathrm{g}}$ of each sample. Given the estimated $\pm 1^{\circ} \mathrm{C}$ error on $\mathrm{T}_{\mathrm{g}}$, the cooperativity plots of the irradiated samples were manually translated so that they all intersected at $\mathrm{T}_{\mathrm{g}} / \mathrm{T}=1$. None of these adjustments exceeded the uncertainty range of $\mathrm{T}_{\mathrm{\sigma}}$. The VFT fits extrapolated towards lower temperatures were represented in Fig. 4 instead of the data due to the experimental $\tau_{\mathrm{H}-\mathrm{N}}$ being smaller than $1 \mathrm{~s}$ (see Fig. 2).

The $\mathrm{T}_{\mathrm{g}}$-scaled plot in Fig. 4 visually emphasizes the influence of irradiation on the temperature dependence of the relaxation times. Corresponding fragilities $\mathrm{m}$ were obtained by extracting the slope at $\mathrm{T}_{\mathrm{g}} /$ $\mathrm{T}=1$ from the cooperativity plots in Fig. 4 .

Fig. 5 reports the evolution of fragility with respect to ionizing dose, for the neat and filled materials. The fragility of both the pristine samples is approximately 111 , which is in good agreement with existing literature: $m$ is generally about 100 in linear PDMS $[4,11]$ as well as in linear PMPS [6,36] and values up to 110 were reported for PDMS elastomers [16]. These are high fragility values given the flexibility of the polysiloxane backbone that should lead to low fragilities. Kunal et al. [37] explained these high fragilities in terms of side group stiffness relatively to the backbone, which is high in polysiloxanes regardless of the side groups being methyls or phenyls. Thus, the fragilities of PDMS and PMPS are approximately the same while PMPS has a higher $T_{g}$ than PDMS due to the phenyl side groups being bulkier than the methyl ones.

The fragility of both materials increases linearly with increasing ionizing dose. This moderate fragility increase $(\sim+16 \%$ for the highest dose level) suggests an increase in intermolecular coupling, leading to higher cooperativity of the $\alpha$-relaxation as the polysiloxane network crosslinks. If these materials display high fragilities in their pristine state due to relative side groups/backbone stiffness (intramolecular

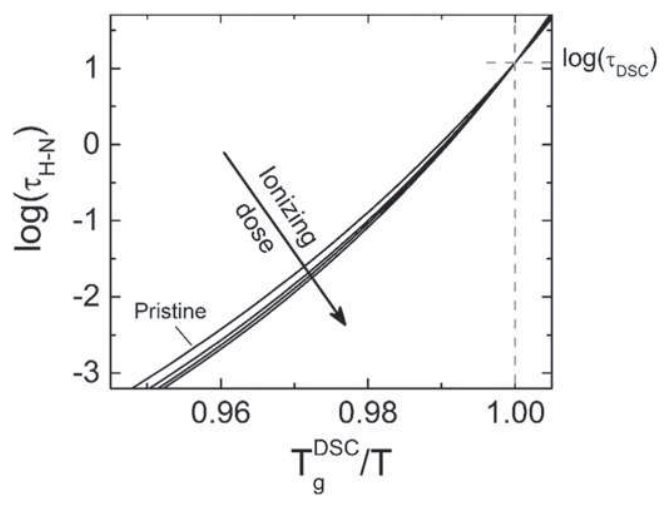

Fig. 4. Cooperativity plot corresponding to the VFT fits in Fig. 2.

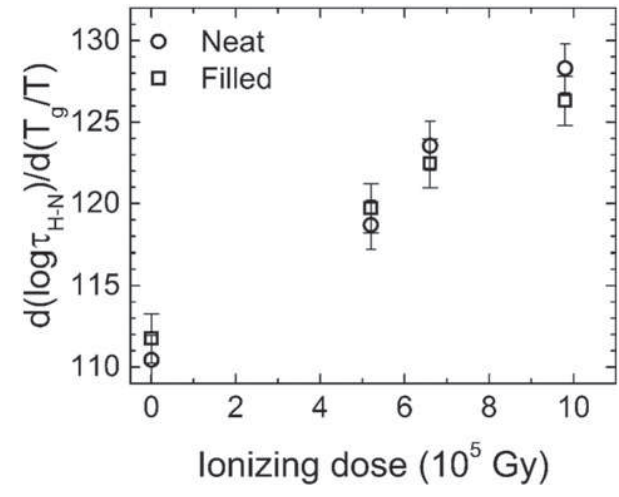

Fig. 5. Evolution of fragility with respect to ionizing dose for the neat and filled materials.

origin), the origin of their increasing fragility with crosslink density is intermolecular.

Schroeder and Roland [11] came to similar conclusions with chemically crosslinked PDMS networks, which brings more insight into this study. In one hand, chemical crosslinking (polyaddition) of these two components-RTV silicone rubbers mainly proceeds through the formation of silethylene links ( $\mathrm{Si}-\mathrm{CH}_{2}-\mathrm{CH}_{2}-\mathrm{Si}$ ) [13]. On the other hand, ionizing radiation-induced crosslinking of these materials primarily proceeds through the formation of $\mathrm{SiO}_{3}$ bonds [1]. Therefore, the nature of the crosslinks involved in the silicone network stiffening does not seem to have a significant impact on the evolution of the molecular mobilities.

3.2.2. The increase in the thermal expansion coefficient of free volume $\alpha_{f}$

Böhmer et al. [30] derived an expression of $m$ in terms of the VFT fit parameters (Eq. (6)).

$$
\mathrm{m}=\frac{\mathrm{DT}_{\infty} / \mathrm{T}_{\mathrm{g}}}{\ln (10)\left(1-\frac{\mathrm{T}_{\infty}}{\mathrm{T}_{\mathrm{g}}}\right)^{2}}
$$

where $T_{\infty}$ is the Vogel temperature, $T_{g}$ the calorimetric glass transition temperature and $\mathrm{D}$ the strength parameter related to the VFT parameters by $\mathrm{DT}_{\infty}=\left(\alpha_{\mathrm{f}}\right)^{-1}$.

Eq. (6) shows that $\mathrm{m}$ is proportional to $\mathrm{D}$ and therefore inversely proportional to $\alpha_{\mathrm{f}}$. The observed increase in $\alpha_{\mathrm{f}}$ (see Fig. 3) seems incoherent with the increase in fragility observed in Fig. 5. This apparent inconsistent behavior of $\alpha_{\mathrm{f}}$ stresses the complicated effect of $T_{\infty}$ on fragility. Two physical arguments accounting for the increase in $\alpha_{\mathrm{f}}$ are proposed.

The general characteristic length scale (or equivalently size of cooperatively rearranging regions) of the glass transition was estimated around 1-2 nm by Donth [38], i.e. much smaller than the distance between crosslinks, even in the most crosslinked of samples. Therefore, stating that certain mobilities may be enhanced by crosslinking is not incompatible with the global network stiffening indicated by the increases in mechanical modulus (which is directly dependent on the density of crosslinks) on the rubber plateau and calorimetric $\mathrm{T}_{\mathrm{g}}$ : for instance, the appearance of rigid crosslinks may involve the disruption of prior physical bonding in between newly formed crosslinks.

Another possible physical origin of the apparent inconsistent behavior of $\alpha_{\mathrm{f}}$ resides in the evolution of side groups upon irradiation and their role in free volume. As evidenced by Charlesby [39], silicone degradation upon irradiation mainly involves side groups scissions, resulting in $\mathrm{H}_{2}, \mathrm{CH}_{4}$ and $\mathrm{C}_{2} \mathrm{H}_{6}$ outgassing. At localized scale, the silicone backbone mobility may be enhanced in the vicinity of a methyl side group that was either removed or degraded to a smaller form such as $\mathrm{Si}-\mathrm{H}$. Additionally, the phenyl side groups are particularly resistant to ionization (the ejection of an electron is compensated by the ring structure [40]). Thus expected increasing phenyl/methyl side groups ratio upon 
irradiation is also coherent with the localized molecular mobility enhancement due to the decrease in methyl side groups.

\subsubsection{Shape of the $\alpha$-relaxation loss peak}

Schönhals and Schlosser [35] formulated a simple phenomenological model (Eqs. (7a) and (7b)) that consists in fitting with power laws of frequency the two sides of the dielectric loss peak associated with the dielectric manifestation of the glass transition. In this theoretical framework, the low-frequency exponent $m_{S}-s$ is related to the largescale intermolecular correlations, while the high-frequency exponent $\mathrm{n}_{\mathrm{S}}-\mathrm{s}$ is associated with the small-scale, local motions of the network segments.

$\varepsilon \prime \prime(\omega) \sim \omega^{\mathrm{m}_{\mathrm{S}-\mathrm{s}}}$ with $0<\mathrm{m}_{\mathrm{S}-\mathrm{S}} \leq 1$ for $\omega \ll \omega_{0}$

$\varepsilon \prime \prime(\omega) \sim \omega^{-\mathrm{n}_{S-S}}$ with $0<\mathrm{n}_{S-S} \leq 0.5$ for $\omega \gg \omega_{0}$

where $\omega_{0}$ is the angular frequency at which $\varepsilon^{\prime \prime}$ is maximum.

The analysis of the loss peak shape may equivalently be performed by means of the Havriliak-Negami adjustment parameters $\alpha_{\mathrm{H}-\mathrm{N}}$ and

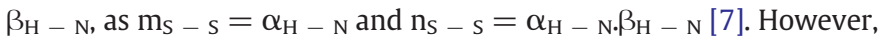
in this study, power laws on both sides of the peak better fitted experimental data than the Havriliak-Negami equation, in particular for the points farther from the peak maximum.

As illustrated in Fig. 6 for the pristine neat and filled samples, the exponents $m_{s}-s$ and $n_{s}-s$ were determined from the $\alpha$-relaxation dielectric loss peaks (not normalized) of the irradiated samples. The evolution of these shape parameters with respect to ionizing dose is represented in Fig. 7.

As the crosslink density of the network increases, $m_{S-s}$ decreases for both materials, but in a more pronounced manner in the neat case ( $-60 \%$ at the highest dose). Under the light of the Schönhals-Schlosser model, this decrease is associated with the promotion of large-scale intermolecular coupling, or cooperativity. Bearing in mind the strong correlation between fragility and nonexponentiality evidenced in polymers by Böhmer et al. [30], the decrease in $\mathrm{m}_{\mathrm{S}-\mathrm{s}}$ is consistent with the increase in fragility observed in Fig. 5. Various authors came to similar conclusions by varying the crosslink density of polymer networks and analyzing the shape of the loss peak [8-10,41,42].

The high-frequency shape parameter $n_{S}-s$ also decreases with increasing ionizing dose, indicating that the segmental dynamics (intramolecular diffusion processes) are slightly hindered by the crosslink densification. This evolution is in good agreement with studies of a polymerizing epoxy network [42] and heterocyclic polymer networks [8] in both of which a less pronounced increase in $n_{S}-s$ than in $m_{S}-s$ was observed with increasing crosslink density. On another hand,

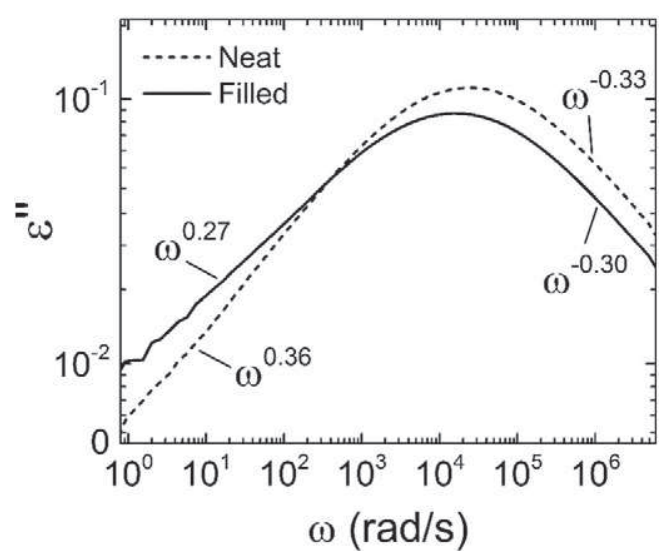

Fig. 6. Dielectric loss peak at $-105^{\circ} \mathrm{C}$ for pristine neat and filled samples, and illustration of the Schönhals-Schlosser model with indication of the $\mathrm{m}_{\mathrm{S}-\mathrm{s}}$ exponents on the left, and of the $\mathrm{n}_{\mathrm{s}-\mathrm{s}}$ exponents on the right.

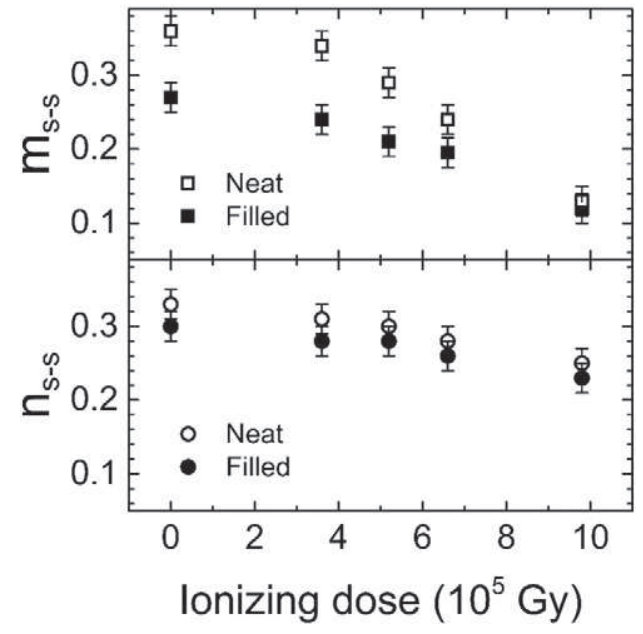

Fig. 7. Evolution of the Schönhals-Schlosser shape parameters $m_{S}-s$ and $n_{S}-s$ with respect to ionizing dose, for the neat and filled materials.

there seem to be a contradiction with a study by Glatz-Reichenbach et al. [9] who observed a constant $n_{S}-s$ regardless of the crosslink density of a styrene-butyl acrylate copolymer. This difference could be material-related but is more likely to originate from different crosslink density ranges: the high ionizing dose levels performed in this study may have allowed reaching higher crosslink densities than those in ref. [9].

\subsection{Filler influence on the evolution of segmental motions under ionizing radiations}

One of the most striking features of Fig. 7 is the discrepancy in the evolutions of $m_{S-s}$ in the two materials, when $n_{S-s}$ is much less influenced by the presence of fillers.

In the pristine state, $\mathrm{m}_{\mathrm{s}-\mathrm{s}}$ is lower in the filled sample than in the neat one. This gap decreases as the crosslink density of the network increases, and the two materials display almost identical values of $\mathrm{m}_{\mathrm{s}}-\mathrm{s}$ at the highest ionizing dose level. On the contrary, neither the calorimetric $T_{g}[1]$ nor the temperature dependence of the relaxation times (VFT parameters, Fig. 3) nor the fragility (Fig. 5) are significantly impacted by the presence of fillers in the polysiloxane matrix. It therefore seems that, from the data at our disposal, only the loss peak shape parameters bring to light the filler influence on the $\alpha$-relaxation of this material.

Three main interpretation schemes may account for this inhomogeneous broadening of the $\alpha$-relaxation towards the low frequencies as a consequence of fillers incorporation and the evolution under ionizing radiations.

Hydrogen bonding evidenced at the interface between the silica fillers and the polysiloxane network [1] could result in cooperativity enhancement of the large-scale motions. Upon irradiation, the H-bonds are progressively replaced with chemical crosslinks $\left(\mathrm{SiO}_{4}\right)$ which also promote cooperativity of the $\alpha$-relaxation, therefore resulting in further decrease of the exponent $m_{s}-s$. In the neat material, the absence of filler-related $\mathrm{H}$-bonds in the pristine state results in a more pronounced decrease in $\mathrm{m}_{\mathrm{s}-\mathrm{s}}$ upon irradiation.

Secondly, a parallel may be drawn with the asymmetrical broadening of the $\alpha$-relaxation loss peak of semicrystalline polymers as compared to the amorphous state. For instance, Hensel et al. [43] observed a significant broadening of the low-frequency side (equivalent to decreasing $\mathrm{m}_{\mathrm{S}}-\mathrm{s}$ ) of the dielectric loss peak while the high-frequency side of the peak remained unaltered (equivalent to unchanged $n_{s}-s$ ). They ascribed this asymmetry to geometrical confinement caused by the crystallites. On one hand, this confinement is effective on largescale motions as their characteristic length is similar to the distance 
between crystallites. On the other hand, the lengths associated with high-frequency local motions are negligible compared to the distance between crystallites. In the filled silicone elastomer, the inorganic fillers could induce geometrical confinement in a similar way.

A third interpretation could account for the inhomogeneous broadening of the $\alpha$-relaxation due to the incorporation of fillers in the matrix. Fragiadakis et al. [44] evidenced a second $\alpha$-relaxation in a PDMS elastomer reinforced with nanometric silica fillers. This second peak at higher temperatures/lower frequencies was associated with a polymer layer (2-3 nm-thick) of reduced mobility located at the interface with the fillers. In the present study, the fillers are not nanometric and very distributed in size, which would not allow the observation of a distinct second peak but could account for the broadening of the main $\alpha$ relaxation peak towards the low frequencies.

Regardless of the interpretation scheme adopted, the highly irradiated samples are similar when it comes to the asymmetrical broadening of the $\alpha$-relaxation. This means that the crosslinking-induced mechanical constraints applied to the polysiloxane matrix dominate the relaxation behavior of these samples. In other words, the presence of fillers no more has impact on the large-scale cooperative motions of the network.

\section{Conclusion}

This study aimed at analyzing the influence of radiation-induced chemical ageing on the molecular mobility of a filled silicone elastomer. Complementary representations and fits of the experimental dielectric loss measured in broadband dielectric spectroscopy led to the following conclusions.

The radiation-induced crosslinking of the polysiloxane matrix resulted in a slowing-down of the $\alpha$-relaxation dynamics, as evidenced by the shifting of the dielectric loss peak towards lower frequencies (equivalent to an increase in the mean dipole relaxation times) and by the increase in the Vogel-Fulcher-Tammann fit parameters with increasing ionizing dose. This slowing-down was accompanied with an inhomogeneous broadening of the dielectric loss peak. The two sides of the loss peak were successfully fitted with power laws of frequency, the exponents of which indicated a greater increase of the lowfrequency side as compared to the high-frequency side. In the framework of the Schönhals-Schlosser model, this asymmetrical broadening was attributed to cooperative intermolecular motions enhancement (low frequencies) as well as a slight hindrance of intramolecular local motions (high frequencies). The increase in cooperativity was also evidenced by an increase in fragility upon irradiation. An apparent inconsistent increase in the thermal expansion coefficient of free volume was also observed, which could be due to the promotion of certain mobilites in between the newly formed crosslinks (possibly involving the disruption of prior physical bonding) and/or a consequence of an increasing phenyl/methyl side groups ratio.

This study evidenced that while chemically produced (mainly $\mathrm{Si}-\mathrm{CH}_{2}-\mathrm{CH}_{2}-\mathrm{Si}$ ) and radiation-induced crosslinks (mainly $\mathrm{SiO}_{3}$ ) have different nature, they influence the dynamic glass transition of silicone in a very similar way.

Another main outcome of this study is related the filler influence on the radiation-induced evolution of the $\alpha$-relaxation. Neither the mean relaxation times nor the Vogel-Fulcher-Tammann fit parameters nor the fragility were affected by the presence of fillers in the matrix. However, a significant discrepancy was observed on the low-frequency exponent of the dielectric loss peak. In the pristine filled sample, the loss peak was broader and more asymmetrical towards low frequencies than in the pristine neat sample. With increasing crosslinking density this discrepancy progressively reduced to the extent that the most irradiated samples showed negligible differences in the shape of the loss peak. Three interpretation schemes were discussed to explain this remarkable behavior: cooperativity enhancement due to hydrogen bonding, filler-related geometrical confinement and immobilized polymer layer at the filler-matrix interfaces. Regardless of the interpretation scheme, it seems that the crosslinking-related mechanical constraints generated in the polysiloxane matrix dominate the relaxation behavior of the filled material at high doses, that is in the highly crosslinked samples.

\section{References}

[1] A. Roggero, E. Dantras, T. Paulmier, C. Tonon, S. Dagras, S. Lewandowski, D. Payan, Inorganic fillers influence on the radiation-induced ageing of a space-used silicone elastomer, 2016. Polym. Degrad. Stab. 128 126-133, , http://dx.doi.org/10.1016/j. polymdegradstab.2016.03.010.

[2] H. Adachi, K. Adachi, Y. Ishida, T. Kotaka, Dielectric relaxation of polydimethylsiloxane, 1979. J. Polym. Sci. Polym. Phys. Ed. 17 851-857, , http://dx.doi.org/10.1002/pol. 1979.180170510 .

[3] K.U. Kirst, F. Kremer, V.M. Litvinov, Broad-band dielectric spectroscopy on the molecular dynamics of bulk and adsorbed poly(dimethylsiloxane), 1993. Macromolecules 26 975-980, http://dx.doi.org/10.1021/ma00057a015.

[4] C.M. Roland, K.L. Ngai, Segmental relaxation in poly(dimethylsiloxane), 1996. Macromolecules 29 5747-5750, , http://dx.doi.org/10.1021/ma960045d.

[5] D. Boese, B. Momper, G. Meier, F. Kremer, J.U. Hagenah, E.W. Fischer, Molecular dynamics in poly(methylphenylsiloxane) as studied by dielectric relaxation spectroscopy and quasielastic light scattering, 1989. Macromolecules 22 4416-4421, http://dx.doi.org/10.1021/ma00202a005.

[6] S. Pawlus, S.J. Rzoska, J. Ziolo, M. Paluch, C.M. Roland, Effect of temperature and pressure on segmental relaxation in polymethylphenylsiloxane, 2003. Rubber Chem. Technol. 76 1106-1115, , http://dx.doi.org/10.5254/1.3547790.

[7] E. Schlosser, A. Schönhals, Dielectric relaxation in polymer solids part 2: application of the new model to polyurethane systems, 1989. Colloid Polym. Sci. 267 133-138, http://dx.doi.org/10.1007/BF01410351.

[8] V.Y. Kramarenko, T.A. Ezquerra, I. Šics, F.J. Baltá-Calleja, V.P. Privalko, Influence of cross-linking on the segmental dynamics in model polymer networks, 2000. J. Chem. Phys. 113 447, , http://dx.doi.org/10.1063/1.481809.

[9] J.K.W. Glatz-Reichenbach, L. Sorriero, J.J. Fitzgerald, Influence of crosslinking on the molecular relaxation of an amorphous copolymer near its glass-transition temperature, 1994. Macromolecules 27 1338-1343, , http://dx.doi.org/10.1021/ ma00084a010.

[10] C.M. Roland, Constraints on local segmental motion in poly(vinylethylene) networks, 1994. Macromolecules 27 4242-4247, , http://dx.doi.org/10.1021/ ma00093a027.

[11] M.J. Schroeder, C.M. Roland, Segmental relaxation in end-linked poly(dimethylsiloxane) networks, 2002. Macromolecules 35 2676-2681, , http://dx.doi.org/10.1021 ma011678h.

[12] B.D. Fitz, J. Mijovic, Segmental dynamics in poly(methylphenylsiloxane) networks by dielectric relaxation spectroscopy, 1999. Macromolecules 32 3518-3527, http://dx.doi.org/10.1021/ma981937b.

[13] F. de Buyl, Silicone sealants and structural adhesives, 2001. Int J. Adhes. Adhes. 21 411-422 http://dx.doi.org/10.1016/S0143-7496(01)00018-5.

[14] D.J. Hill, C.M. Preston, A.K. Whittaker, NMR study of the gamma radiolysis of poly(dimethyl siloxane) under vacuum at $303 \mathrm{~K}, 2002$. Polymer (Guildf). 43 1051-1059, , http://dx.doi.org/10.1016/S0032-3861(01)00711-X.

[15] L. Bokobza, Elastomeric composites. I. Silicone composites, 2004. J. Appl. Polym. Sci. 93 2095-2104, , http://dx.doi.org/10.1002/app.20684.

[16] P. Klonos, A. Panagopoulou, L. Bokobza, A. Kyritsis, V. Peoglos, P. Pissis, Comparative studies on effects of silica and titania nanoparticles on crystallization and complex segmental dynamics in poly(dimethylsiloxane), 2010. Polymer (Guildf). 51 5490-5499, , http://dx.doi.org/10.1016/j.polymer.2010.09.054.

[17] K.E. Polmanteer, Current perspectives on silicone rubber technology, Rubber Chem. Technol. 54 (1981) 1051-1080.

[18] T. Paulmier, B. Dirassen, D. Payan, M. Van Eesbeek, Material charging in space environment: experimental test simulation and induced conductive mechanisms, 2009. IEEE Trans. Dielectr. Electr. Insul. 16 682-688, , http://dx.doi.org/10.1109/TDEI.2009. 5128506.

[19] C.G. Delides, I.W. Shepherd, Dose effects in the crosslinking of irradiated polysiloxane, 1977. Radiat. Phys. Chem. 10 379-385, , http://dx.doi.org/10.1016/ 0146-5724(77)90047-4

[20] D.W. McCarthy, J.E. Mark, S.J. Clarson, D.W. Schaefer, Synthesis, structure, and properties of hybrid organic-inorganic composites based on polysiloxanes. II. Comparisons between poly(methylphenylsiloxane) and poly(dimethylsiloxane), and between titania and silica, 1998. J. Polym. Sci. B Polym. Phys. 36 1191-1200, http://dx doi.org/10.1002/(SICI)1099-0488(199805)36:7<1191\%AID-POLB8>;2-X.

[21] S. Havriliak, S. Negami, A complex plane analysis of $\alpha$-dispersions in some polymer systems, 1966. J. Polym. Sci., Part C: Polym. Symp. 14 99-117, , http://dx.doi.org/10. 1002/polc.5070140111.

[22] (a) H. Vogel, The law of the relation between the viscosity of liquids and the temperature, Phys. Z. 22 (1921) 645-646;

(b) G.S. Fulcher, Analysis of the recent measurements of the viscosity of glasses, 1925. J. Am. Ceram. Soc. 8 339-355, , http://dx.doi.org/10.1111/j.1151-2916. 1925.tb16731.x;

(c) G. Tammann, W. Hesse, Die abhängigkeit der viscosität von der temperatur bie unterkühlten flüssigkeiten, Z. Anorg. Allg. Chem. 156 (1926) 245-257.

[23] G. Adam, J.H. Gibbs, On the temperature dependence of cooperative relaxation properties in glass-forming liquids, 1965. J. Chem. Phys. 43 139, , http://dx.doi.org/10. 1063/1.1696442. 
[24] K.L. Ngai, Universality of low-frequency fluctuation, dissipation, and relaxation properties of condensed matter. I, comments, Solid State Phys. 9 (1979) 127-140.

[25] M.H. Cohen, D. Turnbull, Molecular transport in liquids and glasses, 1959. J. Chem. Phys. 31 1164, , http://dx.doi.org/10.1063/1.1730566.

[26] F. Kremer, A. Schönhals, The scaling of the dynamics of glasses and supercooled liquids, 2003. in: F. Kremer, A. Schönhals (Eds.), Hill, Springer-Verlag, Berlin 2003, pp. 99-129, , http://dx.doi.org/10.1007/978-3-642-56120-7_4.

[27] C.A. Angell, K.L. Ngai, G.B. McKenna, P.F. McMillan, S.W. Martin, Relaxation in glassforming liquids and amorphous solids, 2000. J. Appl. Phys. 88 3113, , http:// dx.doi.org/10.1063/1.1286035.

[28] C. Angell, Relaxation in liquids, polymers and plastic crystals - strong/fragile patterns and problems, 1991. J. Non-Cryst. Solids 131-133 13-31, , http://dx.doi.org/ 10.1016/0022-3093(91)90266-9.

[29] C.M. Roland, K.L. Ngai, Segmental relaxation and molecular structure in polybutadienes and polyisoprene, 1991. Macromolecules 24 5315-5319, , http://dx.doi.org/10. 1021/ma00019a016.

[30] R. Böhmer, K.L. Ngai, C.A. Angell, D.J. Plazek, Nonexponential relaxations in strong and fragile glass formers, 1993. J. Chem. Phys. 99 4201, , http://dx.doi.org/10. 1063/1.466117.

[31] A. Schönhals, Molecular dynamics in polymer model systems, in: F. Kremer, A. Schönhals (Eds.), Broadband Dielectr. Spectrosc, Springer-Verlag, Berlin 2003, pp. 225-293.

[32] I.M. Hodge, Effects of annealing and prior history on enthalpy relaxation in glassy polymers. 4. Comparison of five polymers, 1983. Macromolecules 16 898-902, , http://dx.doi.org/10.1021/ma00240a013.

[33] K.L. Ngai, C.M. Roland, Chemical structure and intermolecular cooperativity: dielectric relaxation results, 1993. Macromolecules 26 6824-6830, , http://dx.doi.org/10. 1021/ma00077a019.

[34] L.A. Dissado, R.M. Hill, A cluster approach to the structure of imperfect materials and their relaxation spectroscopy, 1983. Proc. R. Soc. Lond. A Math. Phys. Sci. 390 131-180, , http://dx.doi.org/10.2307/2397657.
[35] A. Schönhals, E. Schlosser, Dielectric relaxation in polymeric solids part 1. A new model for the interpretation of the shape of the dielectric relaxation function, 1989. Colloid Polym. Sci. 267 125-132, , http://dx.doi.org/10.1007/BF01410350.

[36] D.J. Plazek, K.L. Ngai, Correlation of polymer segmental chain dynamics with temperature-dependent time-scale shifts, 1991. Macromolecules 24 1222-1224, . http://dx.doi.org/10.1021/ma00005a044.

[37] K. Kunal, C.G. Robertson, S. Pawlus, S.F. Hahn, A.P. Sokolov, Role of chemical structure in fragility of polymers: a qualitative picture, 2008. Macromolecules 41 7232-7238, http://dx.doi.org/10.1021/ma801155c.

[38] E. Donth, The size of cooperatively rearranging regions at the glass transition, 1982 J. Non-Cryst. Solids 53 325-330, , http://dx.doi.org/10.1016/0022-3093(82)90089-8.

[39] A. Charlesby, Changes in silicone polymeric fluids due to high-energy radiation, 1955. Proc. R. Soc. A Math. Phys. Eng. Sci. 230 120-135, , http://dx.doi.org/10. 1098/rspa.1955.0116.

[40] A.S. Palsule, S.J. Clarson, C.W. Widenhouse, Gamma irradiation of silicones, 2008. J. Inorg. Organomet. Polym. Mater. 18 207-221, , http://dx.doi.org/10.1007/s10904008-9205-0.

[41] C.M. Roland, K.L. Ngai, D.J. Plazek, The viscoelastic behaviour of networks, 1997. Comput. Theor. Polym. Sci. 7 133-137, , http://dx.doi.org/10.1016/S10893156(97)00016-0.

[42] R. Casalini, A. Livi, P.A. Rolla, G. Levita, D. Fioretto, Self-similarity of dielectric relaxation and conductivity in cross-linking systems, 1996. Phys. Rev. B 53 564-568, http://dx.doi.org/10.1103/PhysRevB.53.564.

[43] A. Hensel, J. Dobbertin, J.E.K. Schawe, A. Boller, C. Schick, Temperature modulated calorimetry and dielectric spectroscopy in the glass transition region of polymers, 1996. J. Therm. Anal. Calorim. 46 935-954 . http://www.akademiai.com.sci-hub. org/doi/abs/10.1007/BF01983612 (accessed June 17, 2015).

[44] D. Fragiadakis, P. Pissis, Glass transition and segmental dynamics in poly(dimethylsiloxane)/silica nanocomposites studied by various techniques, 2007. J. Non-Cryst. Solids 353 4344-4352, , http://dx.doi.org/10.1016/j.jnoncrysol.2007.05.183. 